Int. J. Electrochem. Sci., 13 (2018) $4817-4826$

International Journal of

ELECTROCHEMICAL

SCIENCE

www.electrochemsci.org

\title{
Highly Sensitive Nonenzymatic Glucose Sensor Based on Reduced Graphene Oxide/Ultrasmall Pt Nanowire Nanocomposites
}

\author{
Xianming $\mathrm{Fu}^{1}$, Zhenming Chen ${ }^{2}$, Siyu Shen ${ }^{1}$, Lilan $X u^{1}$, Zhimin Luo ${ }^{3, *}$ \\ ${ }^{1}$ School of Pharmacy and Medical Technology, Putian University, Xueyuan Middle Street 1133\#, \\ Putian 351100, China \\ ${ }^{2}$ Guangxi Key Laboratory of Calcium Carbonate Resources Comprehensive Utilization, College of \\ Materials \& Environmental Engineering, Hezhou University, Xihuan Road 18\#, Hezhou 542899, \\ China \\ ${ }^{3}$ Key Laboratory for Organic Electronics \& Information Displays and Institute of Advanced Materials \\ (IAM), Nanjing University of Posts and Telecommunications, Wenyuan Road 9\#, Yadong New \\ District, Nanjing 210023, China \\ *E-mail: iamzmluo@hotmail.com
}

doi: $10.20964 / 2018.05 .46$

Received: 22 January 2018 / Accepted: 2 March 2018 / Published: 10 April 2018

An amperometric nonenzymatic biosensor for sensitive and selective detection of glucose has been developed by using reduced graphene oxide/ultrasmall platinum nanowire nanocomposites (rGOPtNW) as electrode material. rGO-PtNW displays good electrocatalytic activity towards the oxidation of glucose in alkaline solution. The fabricated biosensor shows good analytical performance including low detection limit $(4.6 \mu \mathrm{mol} / \mathrm{L})$, wide linear range $(0.032-1.89 \mathrm{mmol} / \mathrm{L})$, high sensitivity $(56.11$ $\left.\mu \mathrm{A} \cdot(\mathrm{mmol} / \mathrm{L})^{-1} \cdot \mathrm{cm}^{-2}\right)$, and good anti-interfering ability towards species (uric acid and ascorbic acid) coexisting with glucose in human blood at the work potential of $0 \mathrm{~V}$. It indicated that rGO-PtNW nanocomposite can serve as a promising candidate material for high-performance glucose nonenzymatic biosensors.

Keywords: glucose; biosensor; nonenzymatic sensor; reduced graphene oxide; Pt nanowire

\section{FULL TEXT}

(C) 2018 The Authors. Published by ESG (www.electrochemsci.org). This article is an open access article distributed under the terms and conditions of the Creative Commons Attribution license (http://creativecommons.org/licenses/by/4.0/). 